Experimental Study on Seismic Vibration Control of Stockers in Wafer and LCD Panel Fabs
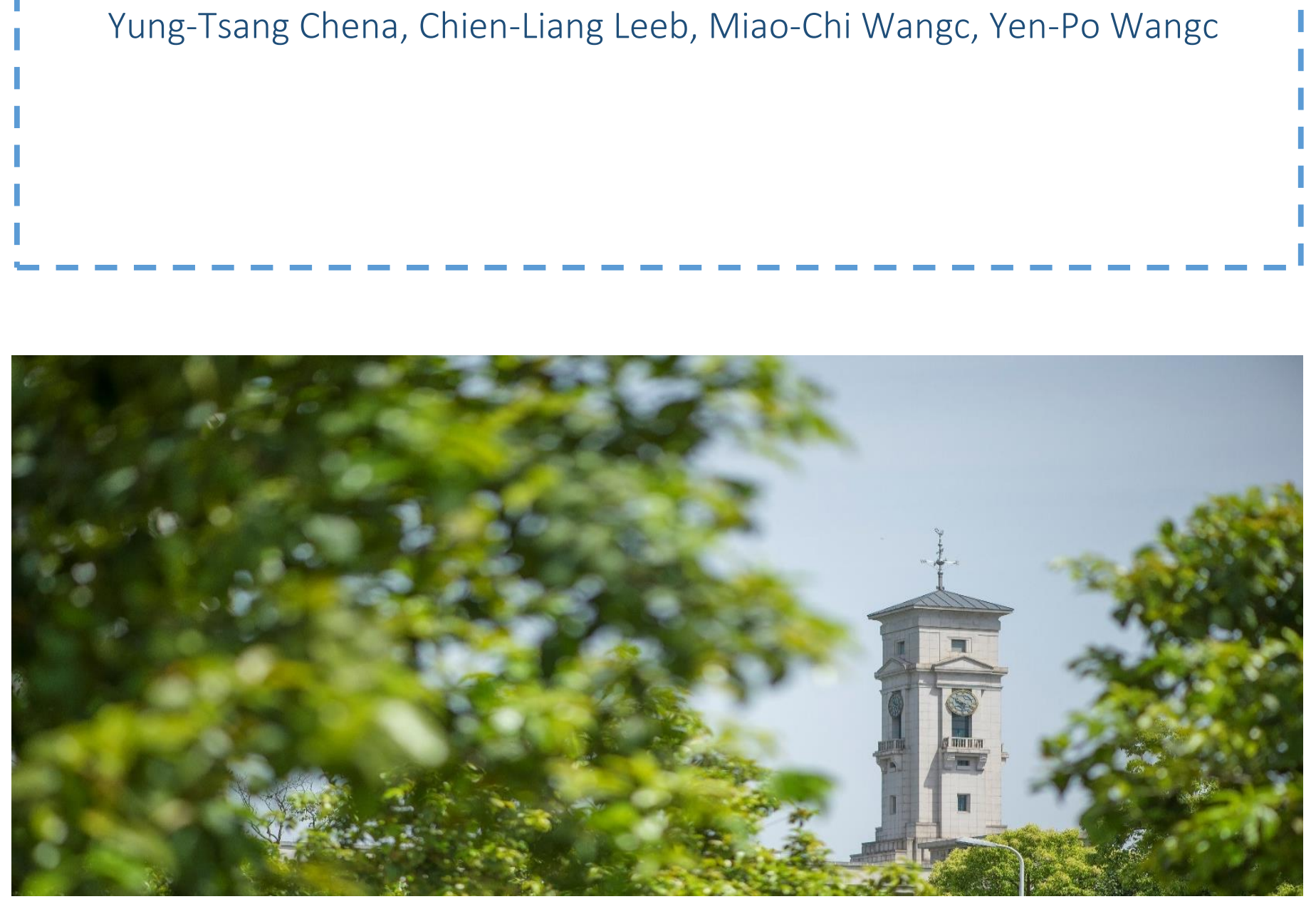
University of Nottingham Ningbo China, 199 Taikang East Road, Ningbo, 315100, Zhejiang, China.

First published 2021

This work is made available under the terms of the Creative Commons Attribution 4.0 International License:

http://creativecommons.org/licenses/by/4.0

The work is licenced to the University of Nottingham Ningbo China under the Global University Publication Licence:

https://www.nottingham.edu.cn/en/library/documents/researchsupport/global-university-publications-licence-2.0.pdf 


\title{
Experimental Study on Seismic Vibration Control of Stockers in Wafer and LCD Panel Fabs
}

\author{
Yung-Tsang Chen ${ }^{\mathrm{a}, *}$, Chien-Liang Lee ${ }^{\mathrm{b}}$, Miao-Chi Wang ${ }^{\mathrm{c}}$, Yen-Po Wang ${ }^{\mathrm{c}}$ \\ ${ }^{a}$ Department of Civil Engineering, University of Nottingham Ningbo China, 199 Taikang \\ East Road, Ningbo 315100, China \\ ${ }^{b}$ School of Civil Engineering, Xiamen University of Technology, 600 Ligong Road, Xiamen \\ 361024, China \\ ${ }^{c}$ Department of Civil Engineering, National Chiao Tung University, 1001 University Road, \\ Hsinchu 300, Taiwan, ROC
}

\begin{abstract}
Automated stocker system is widely used in semiconductor and liquid crystal display (LCD) industries for handling and storage of valuable wafers or glass panels. Massive front opening unified pods (foups) containing wafers, or cassettes storing glass panels, are placed in shelf stockers during manufacturing. Although several preventative measures have been taken, during the past earthquakes, substantial financial loss from the industries were reported, and one of the main causes was attributed to collision of the foups or cassettes and shake off from the shelfs. This paper proposes a methodology of incorporating viscous fluid dampers into the stokers to mitigate their seismic response. Unlike conventionally been done in buildings where dampers are placed between adjacent stories, it is proposed to install dampers in between the ceiling and top of the stocker. Such configuration utilizes the large velocity at the stocker top under vibration, resulting in smaller damper size, and enables a leverage mechanism that requires smaller damper force to resist the stocker's vibration. Both shake table tests and simulation of a full-scale stocker under realistic earthquakes have been conducted. Results indicate that both displacement and acceleration responses of the stocker can be significantly reduced, and dynamic response of the
\end{abstract}

\footnotetext{
* Corresponding Author

Email address: Yung-Tsang.Chen@nottingham.edu.cn (Yung-Tsang Chen)
}

Preprint submitted to Journal of ${ }^{A} T_{E} X$ Templates

March 16, 2021 
stocker under seismic excitations can be well predicted.

Keywords: Wafer fab, LCD panel fab, stockers, seismic energy dissipation, viscous fluid dampers

\section{Introduction}

Locating at the boundary between the Eurasian and the Philippine Sea tectonic plates, Taiwan, an island in East Asia, has seen many earthquakes resulting from movement of the tectonic plates in its history. As a result, implementing 5 seismic design in building codes is compulsory in Taiwan, in order to construct earthquake resistant buildings and infrastructures. Serving as an important base in world supply chain of electronics and computers, Taiwan has set up three major industrial zones, namely Hsinchu, Taichung, and Tainan Science Parks, to accommodate the companies involved in design, testing, and production of these products. Taiwan's economy relies heavily on the high technology industries. In 2019, the three Science Parks posted a combined revenue of NT $\$ 2.63$ trillion (US $\$ 87.8$ billion) [1. Prevent earthquake damage to the buildings and facilities in the Science Parks so as to keep economy growth, has become one of the main priority for the Science Parks' administration bureau. While building codes are designed mainly to provide protection of the lives and property but not content of the buildings, damage to vibration-sensitive manufacturing equipment and consequently shut down of production during earthquakes, which might be inevitable, could impair the country's overall economy significantly.

On February 6, 2016, an earthquake with a Richter magnitude of 6.6 struck Tainan Science Park in the southern part of Taiwan. The recorded peak ground acceleration (PGA) at various sites in the park was around $300 \mathrm{gal}\left(300 \mathrm{~cm} / \mathrm{s}^{2}, 3\right.$ $\mathrm{m} / \mathrm{s}^{2}$, or $0.306 \mathrm{~g}$ ), which is fairly close to the design ground acceleration of $0.33 \mathrm{~g}$ specified in the seismic design code of Taiwan [2]. Although still within the range of the design earthquake acceleration, extensive damage has been reported from various companies in the Science Park. Different from structural damage in the office buildings, factories, or infrastructures that was originally expected, the 
reported loss from the industries was mainly due to damage of manufacturing facilities. Substantial financial loss estimated to be tens of billions of U.S. dollars from the industries have been revealed, in particular, semiconductor and LCD industries reported significant loss due to the earthquake, which, after field investigations, was attributed to the damage of the valuable wafers and glass panels.

In semiconductor and LCD industries, wafers made of silicon are used for the fabrication of integrated circuits chips, while glass panels consisting of a layer of liquid crystal material supported by two glass plates are used in the production of LCD monitors, both of which are crucial and valuable components. Automated stocker system is widely used in these two industries to handle and store the wafers and glass panels during production. Massive front opening unified pods containing wafers, or cassettes storing glass panels, are placed in shelf 40 stockers during manufacturing. The stockers in the automated stocker system are of various sizes, but are generally tall and slim, with small member crosssections, and often made of aluminum alloy. Common height of the stockers used in semiconductor and LCD factories are 4-5 $\mathrm{m}$ and 6-7 $\mathrm{m}$, respectively. Due to the features of the stockers, and the fact that their base are often fixed 45 to the floor slab, actual acceleration imposed on foups and cassettes on the shelf of the stockers are expected to be larger than the floor acceleration during earthquakes. This is escalated by the fact that maximum floor acceleration subjected to major earthquake loading is often amplified over the peak ground acceleration. In the February 6 earthquake, although the PGA was merely 300 gal, the recorded peak floor acceleration (PFA) from various companies ranged from 400 gal to 600 gal, depending on the floor elevation and structural types. As a result, foups or cassettes on the shelf stockers are prone to collide and even shake off during large stocker's vibration, which is evident as has been reported in this earthquake. Remedial measurements to tackle this problem therefore has ${ }_{55}$ become a top priority for company leaders in the industries.

In the literature, very limited research was found in mitigating vibration of factory facilities such as automated stocker system due to earthquakes. In a 
pioneer work by Wang et al. [3], a series of shake table tests were conducted on a stocker that was $4 \mathrm{~m}$ wide, $3.05 \mathrm{~m}$ long, and $7.68 \mathrm{~m}$ high, with a total mass of $5650 \mathrm{~kg}$. Polyvinyl chloride (PVC) panels were used to simulate glass panels in the cassettes. The proposed remedial measurements included (i) installation of stoppers at the edge of the shelf, (ii) installation of braces and (iii) installation of viscous dampers. Results indicated that when the peak ground acceleration of the input excitation was larger than 300 gal, the cassette started to slide and collide with the stopper. The large inertial force from the self-weight of the cassette (about $1000 \mathrm{~kg}$ ) caused the PVC panels to eject from the cassette under impact loading. Results from the stocker with braces installed from bottom to top in all shelfs of the stocker revealed that, although the drift of the stocker decreased due to brace stiffening, the increased lateral stiffness also resulted in large shelf acceleration, which contradicted the purpose of installing the braces. For the case with four viscous dampers installed in the first shelf, results showed also a reduced drift response of the stocker but in a less extent as compared to the braced counterpart; however, the measured shelf acceleration still increased slightly as compared to the original un-reinforced stocker, which failed to meet the design objective.

Another work done by Wang et al. 4 focused on strengthening the joints between the base of the stocker and the floor, as the poor seismic performance of the stocker was deemed to be attributed to the poor detailing of the connectors, leading to rocking of the stocker during earthquakes. In this work, a smaller stocker that was $1.69 \mathrm{~m}$ wide, $3.95 \mathrm{~m}$ long, and $4.18 \mathrm{~m}$ in height with a total mass of $1700 \mathrm{~kg}$, was used as the test frame. Similar to previous work by Wang et al. [3, lateral braces and stoppers at the end of the shelf edge were installed to stiffen and to stop the cassettes from shaking off, respectively. To prevent the stocker from sliding, more foot mounts were also installed. While several improvement was made on the connection details, results from the shake table tests nonetheless indicated that the overall sliding and drift of the frame were reduced, but shelf acceleration was compromised, in particular, the stocker's peak shelf acceleration was amplified by nearly 2.5 times as compared to the 
un-reinforced counterpart. Even with the mounting of the stopper to keep the cassettes from shaking off, the large impact force due to collision of the cassette and stopper caused damage to the stopper, and eventually leading to ejection of the PVC panels.

Viscous fluid dampers are often applied in bridges and buildings to mitigate structural sway, by providing additional damping to the main structures.

${ }_{95}$ They have been proven to adequately protect structures against earthquakes [5, 6, 7, 8, While most of the applications of viscous dampers in civil engineering are on the mitigation of structures due to seismic and wind-induced vibration, in the literature some research works are focused on controlling the vibration of specific objects or building content in the structure. For example, Asfar and Akour [9] presented a numerical study for the suppression of self-excited oscillator using an impact viscous damper. Lin et al. [10] proposed a micro vibration mitigation system using viscous dampers to reduce the vibration in a high-tech building. Hong et. al. [11] presented a three-dimensional analytical study of a hybrid platform on which high-tech equipments are mounted for their vibration mitigation. The literatures mentioned above have proven that small, customized viscous dampers are effective means of reducing the unwanted vibration of objects or building content. However, in the application of adopting viscous fluid dampers in stockers by Wang et al. [3], where four dampers were installed diagonally at first shelf of the stocker, the dampers did not perform well. Although not explicitly shown, the main cause may be attributed to the small inter-shelf drift under given excitations, which restricted the types of dampers that can be used, and this affected the dampers' performance significantly.

In this paper, a practical approach of incorporating viscous fluid dampers into the stokers to mitigate their seismic response is proposed. To tackle the issues with simple yet feasible solution, unlike conventionally been done by Wang et al. 3] where dampers are placed between adjacent shelfs, it is proposed to install dampers in between the ceiling and top of the stocker. Such configuration utilizes the large velocity at the stocker top under vibration, which results in smaller required damper size, and enables a leverage mechanism that demands 


\section{Experimental program}

A test specimen representative of typical stockers used in semiconductor industry is selected at the outset. The test stocker is provided by a semiconductor company, with the same structural details as those used in its factories.

\subsection{Details of test stocker, steel frame, and viscous dampers}

The test specimen is of frame type with shelfs installed at upper half of the stocker, as can be seen in Fig. 1(a), The stocker is $1.35 \mathrm{~m}$ long, $0.44 \mathrm{~m}$ wide, and $4.31 \mathrm{~m}$ tall, with its members made of aluminum alloy (A6N01S-T5). Density, yield strength, Young's modulus, and Poisson's ratio of the aluminum alloy are $2700 \mathrm{~kg} / \mathrm{m}^{3}, 206 \mathrm{MPa}, 69 \mathrm{GPa}$, and 0.33, respectively. To simulate the seismic response of a semiconductor fabrication plant (fab), a one story steel frame is designed to replicate the inter-story movement in one story of the fab, as shown in Fig. 1(b) The steel frame has dimensions $2.1 \times 2.1 \times 4.29 \mathrm{~m}$, with a mass of 742 $\mathrm{kg}$. Two steel plates with a total mass of $600 \mathrm{~kg}$ are placed on top of the frame 145 to simulate the mass of the ceiling. Density, yield strength, Young's modulus, and Poisson's ratio of the steel material (SN400B) are $7850 \mathrm{~kg} / \mathrm{m}^{3}, 235 \mathrm{MPa}$, $200 \mathrm{GPa}$, and 0.3, respectively. The purpose-built frame gives $1 \%$ inter-story drift under the code specified design earthquake intensity of $0.33 \mathrm{~g}$ [2]. 
For the number of dampers to be placed on top of the stocker, since re-

both translation and rotation modes, it is proposed to install two viscous fluid dampers in parallel on two edges of the stocker so that both motions can be controlled. In the experiment, two identical dampers are installed on top of the stocker, with the other end of the dampers attached to a reaction beam which tion beam is laterally supported by the two columns via short linking beams, as shown in Fig. 2(a). Fig. 2(b) shows a closer view of the installed dampers. For optimal performance of the dampers on vibration control of the stocker, a numerical study by Chen [12] was first conducted. From the parametric study table with 4 M10 bolts. The stocker was also laterally supported at its base by stainless steel brackets, which were bolted to the shake table. The one story steel frame simulating the seismic response of a semiconductor fabrication plan was supported by four base piers of $0.43 \mathrm{~m}$ in height, as shown in Fig. 3 Preliminary system identification test of the frame was conducted, and result indicated that the fundamental frequency and damping ratio of the frame were $3.06 \mathrm{~Hz}$ and $0.3 \%$, respectively. Fig. 4 shows photographs of the final test setup. 
After the assembly of the stocker and frame on the shake table, to measure with the seismic dampers), to accommodate the possible scenarios in an earthquake event. It should be noted, however, that for the original stocker without dampers, Kobe earthquake with a PFA scaled to 150 gal was used, to avoid 

displacement of the stocker. Experimental results from shake table tests will be discussed in detail as follows.

\subsection{Kobe Earthquake with $P F A=415$ gal}

As mentioned previously, for the earthquake on February 6, 2016 in Tainan, eration from various companies in the Tainan Science Park ranged from 400 to 600 gal, depending on the floor elevation and structural types. To test if the 
added dampers can provide adequate protection against earthquake damage, Kobe earthquake with a PFA of 416 gal is used at the outset as the input floor

the roof displacement is reduced significantly. A peak response of the original stocker is observed to be $101.2 \mathrm{~mm}$; with the implementation of the damper system, the peak is reduced to $73 \mathrm{~mm}$, equivalent to $28 \%$ response reduction. It 
can also be seen from Fig. 7(b) that the maximum damper stroke is measured as $5.7 \mathrm{~mm}$, which is well within the acceptable damper's stroke of $55 \mathrm{~mm}$. For the Kobe earthquake with a PFA of 416 gal, with the application of the damper system, both acceleration and displacement responses are reduced, indicating that the added seismic dampers can protect the stocker and minimize the risks of shaking off wafers from the stocker shelf.

\subsection{Kobe Earthquake with $P F A=614$ gal}

Since shake table test of the stocker with input Kobe Earthquake at a PFA of 416 gal has shown rather promising results, it is of interest to know whether the added dampers can provide similar protection for earthquakes with higher intensity. To this end, the same Kobe Earthquake but with a higher PFA of 614 gal is used, as up to 600 gal PFA was observed from the onsite measurement.

Fig. 8 shows the comparison of response acceleration and displacement of the stocker subjected to Kobe earthquake with a PFA of 614 gal, while Table 2 summarizes the test results. As can be seen from Fig. 8 and Table 2, for the original un-controlled stocker, when it is compared with previous results (Kobe earthquake with 416 gal PFA as input), the stocker shows overall higher acceleration response at its top and top shelf for all four sensors (ASTK1-4). The peak accelerations at ASTK1,2,3, and 4 are 2745, 3587, 2365, and 3163 gal, respectively. When the dampers are added, the peak accelerations drop to 1097, 1105, 1095, and 1076 gal at ASTK1,2,3, and 4, respectively, corresponding to reductions of peak acceleration of $60 \%, 69 \%, 54 \%$, and $66 \%$. Similar response reduction can be observed from the root-mean-square acceleration response. In this scenario, the stocker with the added dampers show overall higher response reduction as compared to the previous test with a PFA of 416 gal. Torsion of the stocker is also well controlled by the dampers, as the maximum acceleration on two ends of the stocker are fairly close. Moreover, the measured displacement response of the stocker top, as can be seen from Fig. 8(b), is reduced significantly (up to $69 \%$ R.M.S. reduction as shown in Table 2). The maximum stroke of the damper $(8.1 \mathrm{~mm})$, although increases slightly as compared to the case for 
$\mathrm{PFA}=416 \mathrm{gal}(5.7 \mathrm{~mm})$, is still well within the acceptable limit of $55 \mathrm{~mm}$. In the stocker subjected to Kobe earthquake with a PFA of 717 gal. As can be seen from Fig. 9 (a), the roof and shelf acceleration can be as high as 4188 and 3693 gal, respectively, if un-protected. After the application of seismic dampers, the maximum roof and shelf acceleration both drop. Results summarized in Table 3152 show that, if the stocker is equipped with the seismic dampers, the peak accelerations at left (ASTK2) and right (ASTK1) sides of the stocker top drop from 4188 to 1321 gal and from 3205 to 1378 gal, respectively, equivalent to $68 \%$ and $57 \%$ reduction. At top shelf where foups or cassettes are hosted, the maximum acceleration at left side of the top shelf (ASTK4) drops from 3693 to 1340 gal (51\% reduction). Torsional effect of the stocker is well controlled, similar to previous observation for the stocker subjected to earthquakes with lower PFA. It can be seen from Fig. 9 (b) that maximum drift of the stocker at $\mathrm{PFA}=717$ gal has reached $175 \mathrm{~mm}$; however, with the implementation of 325 the stocker are both well controlled.

\subsection{Kobe Earthquake with $P F A=717 \mathrm{gal}$}

Shake table tests of the stocker subjected to Kobe Earthquake with PFA=416 and 617 gal have shown very promising results in reducing both the acceleration and displacement responses; however, to accommodate possible scenarios in future earthquakes, an earthquake event with a PFA larger than 617 gal may worth exploring. To this end, the Kobe earthquake with a PFA of 717 gal, to represent an ideal case of a 700 gal earthquake, is adopted as the seismic input at floor level.

Fig. 9 shows the comparison of response acceleration and displacement of to 1226 gal (67\% reduction), while at right side (ASTK3) it drops from 2761 two viscous dampers, it has dropped to $124.2 \mathrm{~mm}$. The maximum stroke of the damper, although with the relatively large PFA, is $11.4 \mathrm{~mm}$ and is still well within the limit of $55 \mathrm{~mm}$. This again proves that the proposed retrofit scheme utilizes the large velocity at the stocker top under vibration, thus even 
dampers with small damping coefficient could provide the required damper force. The proposed scheme also integrates the stocker into the ceiling, which enables an efficient leverage mechanism for seismic control of the stocker, as the long moment arm measured from the base to the stocker top reduces the required damper force to resist the stocker's vibration.

Table 2 summarizes the results of the stocker to Kobe earthquake with PFAs of 415, 614, and 717 gal. As can be seen from Table 2, both acceleration and displacement responses of the stocker are reduced with the use of viscous dampers, regardless of the earthquake intensity considered, in both pear and root-mean-square responses. It should be noted that the excellent performance could not be achieved by using internal bracing or dampers in the stocker, as 340 have been attempted by Wang et al. [3].

\section{Simulation of the Frame-Stocker-Damper System}

In addition to the experimental program of the stocker which confirms the feasibility of the proposed reaction beam-viscous damper system, in this paper, a finite element analysis aimed at simulating the seismic response of the stocker is also conducted. The finite element software ETABS is used to create the structural model for the stocker and to simulate the response of the stocker under input earthquakes. Results from finite element modeling will be compared with those from shake table testes, to verify the accuracy of the output and to prove whether the modeling provides a reliable and efficient means to support the design of stockers with the proposed reaction beam-viscous dampers system.

\subsection{System Identification}

As shake table tests of the stocker have been conducted, it will be beneficial for later analysis if the dynamic characteristic of the test stocker, including natural frequencies and damping ratios, can be identified via system identifica-

355 tion using experimental data. In this study, system identification using ARX (Auto-Regressive with eXogenous) 14, a linear regression model, is conducted and described briefly below. 
Consider a single input and single output ARX mode, the mathematical model can be described using a linear differential equation as:

$$
y[k]+a_{1} y[k-1]+\ldots+a_{n_{a}} y\left[k-n_{a}\right]=b_{0} x[k]+b_{1} x[k-1]+\ldots+b_{n_{b}} x\left[k-n_{b}\right]+e[k]
$$

where $y[\cdot]$ and $x[\cdot]$ represent respectively the output and input signal of the system, $a_{i}$ and $b_{i}$ respresent the coefficients for output and input signal, respectively, $n_{a}$ and $n_{b}$ are the dimensions of the output and input signal. By taking $\mathrm{z}$ transform of Eq. (1), the frequency response function of the system can be written as:

$$
H[z]=\frac{y[z]}{x[z]}=\frac{b_{0}+b_{1} z^{-1}+\ldots+b_{n_{b}} z^{-n_{b}}}{1+a_{1} z^{-1}+\ldots+a_{n_{a}} z^{-n_{a}}}
$$

where $y[z]$ and $x[z]$ are the $z$ transform of $y[k]$ and $x[k]$, respectively, $z=e^{i 2 \pi f \Delta t}$, $f$ and $\Delta t$ are the frequency and sampling period of the system, respectively. The roots to $y[z]=0$ are called "zeros", and they are associated with the amplitude of the vibration modes. The roots to $x[z]=0$ are called "poles", and they are associated with the frequencies and damping ratios of the system. They have the following relations:

$$
\begin{gathered}
f_{j}=\frac{1}{2 \pi \Delta t} \sqrt{\left(\ln r_{j}\right)^{2}+\phi_{j}^{2}} \\
\xi_{j}=-\frac{\ln r_{j}}{\sqrt{\left(\ln r_{j}\right)^{2}+\phi_{j}^{2}}}
\end{gathered}
$$

where $r_{j}=\sqrt{p_{j} \bar{p}_{j}}, p_{j}$ is the $j-t h$ root to $x[z]=0$ and $\bar{p}_{j}$ is the complex conjugate of $p_{j}, \phi_{j}=\arctan \left[\frac{\operatorname{Im}\left(p_{j}\right)}{\operatorname{Re}\left(p_{j}\right)}\right], \operatorname{Re}\left(p_{j}\right)$ and $\operatorname{Im}\left(p_{j}\right)$ are the real part and imaginary part of $p_{j}$, respectively.

Therefore, if the system coefficients $a_{i}$ and $b_{i}$ in Eq. (1) can be identified, the frequency response function, natural frequencies and damping ratios of the system can be obtained. In the ARX model, the measured acceleration history of the shake table is treated as the input, while the response acceleration on the frame top is treated as the output. Since two accelerometers (ASTK1 and ASTK2) are installed at two sides of the stocker, and there is obvious torsional 
effect in the test model, the average acceleration of the two sensors is used as the output in the translational direction of the stocker, namely:

$$
A S T K^{\text {translation }}=\frac{A S T K 1+A S T K 2}{2}
$$

The torsional response of the stocker can be extracted from subtracting ASTK2 from ASTK1 first, followed by dividing by the length between the two accelerometers $\left(l_{s}\right)$ as:

$$
A S T K^{\text {torsion }}=\frac{A S T K 1-A S T K 2}{l_{s}}
$$

Since translational and rotational responses can be obtained from Eqs. (5) and (6), respectively, both translational and rotational modes of vibration can be extracted. For the one-story steel frame, from experimental results there is no obvious torsion thus only acceleration response in translational direction is identified.

For system identification purpose the frame and the stocker are subjected to Kobe Earthquake with different PFA at their base. Figure 10 shows the Fourier amplitude spectrum of the stocker in translational and rotational directions with different earthquake intensity, while Table 3 summarizes the natural frequencies and damping ratios from system identification of the stocker and frame. It can be seen from Table 3 that, when the PFA= 129 gal, in the translational direction natural frequencies and damping ratios for modes 1 and 2 are $1.84 \mathrm{~Hz}$ and $4.17 \%$ and $3.00 \mathrm{~Hz}$ and $5.35 \%$, respectively. From Figure 10(a) the first mode's peak is much larger than the second mode, indicating that mode 1 should be the translational model. It can also be seen from Table 3 that in the rotational direction natural frequencies and damping ratios for modes 1 and 2 are $1.84 \mathrm{~Hz}$ and $5.72 \%$ and $3.03 \mathrm{~Hz}$ and $2.52 \%$, respectively. From Figure $10(\mathrm{~b})$ the peak for the second mode is much larger than the first mode, implying the second mode should be torsional mode of the stocker. Therefore, by combining the observations from the two amplitude spectra, one can summarize that the first mode of the stocker is a translational mode, and its frequency and damping ratio are respectively $1.84 \mathrm{~Hz}$ and $4.17 \%$. The second mode is a torsional mode, and its frequency and damping ratio are $3.03 \mathrm{~Hz}$ and $2.52 \%$, respectively. Similar trend 
is also observed in the case for $\mathrm{PFA}=217 \mathrm{gal}$, as can be seen from Figure 10.(c)

and (d), in which from system identification natural frequencies and damping ratios for first (translation) and second (torsion) modes of vibration are $1.83 \mathrm{~Hz}$ and $5.00 \%$ and $3.03 \mathrm{~Hz}$ and $1.53 \%$, respectively. The slight increase in damping ratio as compared to that extracted from the structural response subjected to the same earthquake with $\mathrm{PFA}=129$ gal may be attributed to the increase in joint friction as a result of larger stocker's vibration. For the one-story frame there is no obvious torsion and the natural frequency of the first mode is 3.07 Hz. Damping ratio is $0.07 \%$ when the PFA equals 129 gal, and it increases slightly to $0.24 \%$ when the PFA reaches 217 gal.

\subsection{Structural Modeling}

Since the one-story frame is used to replicate one story of the fabs, the model of the frame in ETABS is first established. The frame has dimensions $2100 \times 2100 \times 4288 \mathrm{~mm}$ and is supported on four piers that are $430 \mathrm{~mm}$ above the shake table. Considering the thickness $(20 \mathrm{~mm})$ of the bottom flange of the support beam, the rigid zone factor and rigid zone length at bottom joint of the frame in ETABS are set as 100\% of section depth and $450 \mathrm{~mm}$, respectively. The rigid zone factor and length for the beam column joint at top are set as $50 \%$ of section depth. The test stocker is $1355 \mathrm{~mm}$ long, $440 \mathrm{~mm}$ wide, and $4310 \mathrm{~mm}$ tall, with input material properties described in section 2.1. The stocker is bolted to a horizontal frame and the frame was fixed to the shake table; therefore, the boundary condition is initially set as fix-connection. Since from the experimental program obvious torsion of the stocker was observed, which possibly is due to local damage/defect in the structural members, it is decided to set 4 of the 8 bolting points to be pin-connection and reduce the cross-sectional area of 2 of the 4 columns by $50 \%$, to simulate the torsional behavior in the test stocker under vibration. Results from ETABS indicate that the frequencies of the first (translation) and second (torsion) modes are 2.19 and $3.03 \mathrm{~Hz}$, respectively. To consider earthquakes with varied PFA, an overall damping ratio of $4 \%$ is assigned to the stocker. 
For the damper configuration in ETABS, the nonlinear element "NLLINK"

415 to simulate the added linear viscous dampers with damping coefficient $=5$ N.s/mm. The aluminum reaction beam with 40 by $40 \mathrm{~mm}$ cross-section together with two supporting $\mathrm{H}$ beam on two sides and one $\mathrm{H}$ beam in the middle overhung from the ceiling are also created in the model to simulate the reacthe stocker-frame model in ETABS in shown in Fig. 11(a), while Fig. 11(b) shows the location of the two accelerometers at the top of the stocker. The Kobe earthquake with varied PFAs, similar to that used in the experimental program, is adopted as the seismic input. By performing a dynamic analysis 425 of the stocker in ETABS, system's responses can be extracted. The feasibility of using the commercially available structural analysis software can be assessed by comparing simulation results with experimental measurements, in which the acceleration at top of the stocker (ASTK1 and ASTK2) and the stocker's overall displacement are the key elements for comparison.

\subsection{Result Comparison}

\subsubsection{Original Uncontrolled Stocker}

Comparison of the test and simulation results are first conducted on the original structure subjected to Kobe earthquake with a PFA of 88 gal. Accelerometers (ASTK1-4), laser displacement sensors (LD1-3) and a linear potentiometers movement at center of the stocker top from the shake table tests. Response from the same sensor locations are also derived from ETABS for comparison purpose. Although not explicitly shown, the first mode frequency from the shake table test via system identification is $1.83 \mathrm{~Hz}$, while the frequency from simulation the stocker changes with the magnitude of the PFA and when subjected to different input earthquakes, result from system identification may show different first mode frequency, whereas ETABS gives the same frequency regardless of 
the seismic input, the difference in first natural frequency is deemed acceptable.

Table 4 shows the comparison of the stocker's response to Kobe earthquake with a PFA of 88 gal. As can be seen from Table 4, response acceleration from ETABS generally shows good agreement in peak acceleration, with maximum difference at ASTK3. Simulation results are, in general, larger than those from the experiments. This may be attributed to the damping ratio setup (4\%) in ETABS, as actual damping of the stocker may be larger than $4 \%$, thus causing the smaller acceleration response in simulation. It can also be seen from Table 4 that the maximum stocker displacement at top center from experiments agrees reasonably well with the ETABS' output, with a $12.5 \%$ difference.

\subsubsection{Kobe Earthquake with $P F A=415$ and $614 \mathrm{gal}$}

Fig. 12 shows the comparison of the test results and the output from ETABS under Kobe earthquake with an achieved PFA of 416 gal. As can be seen from Fig. 12(a), the overall acceleration responses at stocker top from the test and the simulation are reasonably close. The test stocker shows a slightly larger response acceleration in both sensor locations, with a difference about $12 \%$ in maximum acceleration response. It is worth noting that the acceleration at both sides of the stocker are fairly close, indicating that the torsional effect observed in the original stocker is well under control. Fig. 12(b) shows the comparison of the stocker's displacement history. A big difference is observed in the stocker's displacement, as can be seen in Fig. 12(b). This may be attributed to the fact that in the experimental setup the stocker's displacement relative to the shake table is calculated indirectly from the recorded stocker's displacement relative to the ground (LD3), the shake table movement relative to the ground (GD), and two dampers' displacement (LD1-2) as follows:

$$
\text { Stocker's Disp. }=(L D 3-G D)+(L D 1+L D 2) / 2
$$

455

where $(L D 3-G D)$ gives the displacement of the steel frame relative to the shake table, and $(L D 1+L D 2) / 2$ measures relative displacement between the stocker and the steel frame at top center. This indirectly calculated displacement of the 
stocker may bring about accumulated errors from all the gauge measurements.

In addition to the input Kobe earthquake with a PFA of 400 gal, in the ETABS simulation the target PFA is further increased to 600 gal, as it is the highest floor acceleration observed in the past earthquake events in the Science Parks in Taiwan. Fig. 13 shows the comparison of test results and the output from ETABS of the stocker under Kobe earthquake with an achieved PFA of 614 gal. It can be seen from Fig. 13(a) that, the ETABS simulation shows very similar response acceleration from both accelerometers. The differences in maximum acceleration in stocker top is about $2 \%$, which shows very good agreement between the simulation and the experiment. Fig. 13(b) shows the comparison of the stocker's displacement history. As can be seen from Fig. 13(b), the difference in the test and simulation is significant, similar to that observed in the case with PFA=416 gal. The large difference may be attributed to measurement errors in one or more of the gauges that inevitably accumulated through obtaining indirectly the stocker's displacement. Although not explicitly shown, in simulation the two dampers in both earthquakes (PFA=416 and 614 gal) exhibit very small damper displacement (less than $10 \mathrm{~mm}$ ). This small damper displacement is consistent with that from the experiments.

Hysteresis loops are often adopted as a measure of the performance of viscous dampers subjected to dynamic loading. Comparison of the hysteresis energy dissipation of the dampers can also be made to verify simulation results with experiments. However, since no load cells were installed in the test setup, herein only results from ETABS simulation are presented. The hysteresis loops of the two viscous dampers at top of the stocker are shown in Fig.14. It can be seen from Fig.14 that, due to asymmetry in lateral stiffness of the columns of the stocker, the hysteresis loops of the two dampers are not identical. The seismic energy dissipation, in terms of the enclosing area of the hysteresis, is larger in 485 damper 2 than that in damper 1 for both earthquakes. It can also be seen from Fig.14 that the energy been dissipated increased with increasing earthquake intensity, which is expected as larger damper force is involved in a more violent earthquake scenario. 


\section{Conclusion}

490 tal display industries to retrofit the stockers in the automated stocker system for protecting the valuable wafers and glass panels under earthquake events. The proposed approach incorporates a reaction beam extended from the ceiling and viscous fluid dampers into the stockers to mitigate their seismic response. By tactfully placing the viscous fluid dampers on top of the stocker and treating ceiling as the reaction wall, the large velocity at stocker top under vibration can be fully utilized, resulting in smaller damper size and enables a leverage mechanism that requires smaller damper force to resist stocker vibration. Results from the shake table tests indicate that both acceleration and sway of the stocker can be minimized, even at a peak floor acceleration of 717 gal earthquake. To verify the proposed approach and to extend the research impact, a simulation using commercially available engineering software ETABS is also conducted. Results from ETABS simulation agree reasonably well with the shake table test, indicating that dynamic response of the stocker equipped with the reaction beam-viscous dampers system under seismic excitations can be well

predicted.

In finding engineering solutions to improve seismic performance of the stockers, it is important to reproduce the experimental results. This research adopts the commercially available software to verify the experimental results so that reproducibility of the test results can be made, which could give structural engineers more confidence in aseismic design of stockers and speed up the design process. The proposed technique has found industrial applications, e.g. the reaction beam-viscous dampers system has been adopted by the Macronix International Co. LTD (MXIC) for seismic retrofit of the existing stockers in their fabs. As a result of the advantages brought by the proposed research, the insurance sector has shown great interests and strong support, in the form of a premium discount in risk insurance for the companies. 


\section{Acknowledgements}

The authors are grateful to the sponsorships and the efforts by MXIC and

520

[3] J. Wang, J. Hwang, W. Lin, F. Lin, C. Tsai, P. Chen, Shockproof experimental study of automated stocker system in the high-tech factory, Open Journal of Earthquake Research 2 (2013) 47-59.

[4] J. Wang, J. Chai, C. Lin, Z. Lin, C. Chang, S. Chang, The shockproof

Jardine Lloyd Thompson Limited who accept the proposed research and make it a state-of-the-practice. This work is supported by Ningbo Science and Technology Bureau under Commonweal Research Program with project code 2019C50017 and a research grant with project code A0060 from Ningbo Nottingham New Material Institute.

[1] E. Committee, Science and technology news march 9th, Report, Ministry of Science and Technology, Taipei, Taiwan (2020).

[2] E. Committee, Seismic design code and commentary for buildings, Report, Construction and Planning Agency, Ministry of Interior Affair, Taipei, Taiwan (2011).

study for automation stocker system and high-raised floor, Journal of Architecture, Architectural Institute of Taiwan 89 (2014) 177-193.

[5] A. Reinhorn, C. Li, M. Constantinou, Experimental and analytical investigation of seismic retrofit of structures with supplemental damping, part i: fluid viscous damping devices, Tech. Rep. NCEER-95-0001, National Center for Earthquake Engineering Research, State University of New York at Buffalo, NY (01 1995).

[6] M. Constantinou, T. Soong, G. Dargush, Passive energy dissipation systems for structural design and retrofit, Multidisciplinary Center for Earthquake Engineering Research, State University of New York at Buffalo, NY, 1998. 
[7] T. Soong, B. Spencer Jr, Supplemental energy dissipation: state-of-the-art and state-of-the-practice, Engineering Structures 24 (3) (2002) 243-259.

[8] D. Taylor, History, design, and applications of fluid dampers in structural engineering, Taylor Devices, Inc., Available: https://www.taylordevices.com/custom/pdf/tech-papers/68HistoryDesignApplication.pdf [Accessed June 16 2019], 2013.

[9] K. Asfar, S. Akour, Optimization analysis of impact viscous damper for controlling self-excited vibrations, Journal of Vibration and Control 11 (1) (2005) 103-120.

[10] T. Lin, C. Chen, K. Chang, C. Lin, J. Hwang, Mitigation of micro vibration by viscous dampers, Earthquake Engineering and Engineering Vibration 8 (2009) 569-582.

[11] S. Hong, S. Zhu, Y. Xu, Three-dimensional vibration control of high-tech facilities against earthquakes and microvibration using hybrid platform, Earthquake Engineering and Structural Dynamics 39 (2010) 615-634.

[12] S. Chen, A study on sesimic vibration control of automated stocker system using customized fluid dampers for semiconductor industry, Master's thesis, Department of Civil Engineering, National Chiao Tung University (July 2017).

[13] H. Chiu, A compatible baseline correction algorithm for strong-motion 565 data, Terrestrial, Atomospheric and Oceanic Science 22 (2) (2012) 171180.

[14] L. Ljung, System Identification - Theory for the User, 2nd Edition, Prentice-Hall, Upper Saddle River, NJ, 1999. 
Table 1: Component test result

\begin{tabular}{ccccc}
\hline \hline $\begin{array}{c}\text { Freq. } \\
(\mathrm{Hz})\end{array}$ & $\begin{array}{c}\text { Ampl. } \\
(\mathrm{mm})\end{array}$ & $\begin{array}{c}\text { Target } C \\
(\mathrm{~N} \cdot \mathrm{s} / \mathrm{mm})\end{array}$ & $\begin{array}{c}\text { Achieved } C \\
(\mathrm{~N} \cdot \mathrm{s} / \mathrm{mm})\end{array}$ & $\begin{array}{c}\text { Max. Force } \\
(\mathrm{N})\end{array}$ \\
\hline 0.1 & 55 & 4.9 & 4.99 & 190 \\
0.5 & 55 & 4.9 & 5.22 & 1103 \\
1 & 44 & 4.9 & 5.05 & 1973 \\
\hline \hline
\end{tabular}


Table 2: Summary of the test results for Kobe earthquakes.

\begin{tabular}{|c|c|c|c|c|c|}
\hline Achieved & & w/o dampers & $\mathrm{w} /$ dampers & & \\
\hline $\begin{array}{l}\text { PFA } \\
\text { (gal) }\end{array}$ & Sensor & $\begin{array}{c}\text { Peak Acc. } \\
\text { (gal) }\end{array}$ & $\begin{array}{c}\text { Peak Acc. } \\
\text { (gal) }\end{array}$ & $\begin{array}{c}\text { Reduction } \\
(\%)\end{array}$ & $\begin{array}{c}\text { Reduction } \\
(\%)\end{array}$ \\
\hline \multirow{7}{*}{416} & ASTK1 & 1853 & 877 & 53 & 41 \\
\hline & ASTK2 & 2422 & 916 & 62 & 63 \\
\hline & ASTK3 & 1596 & 852 & 47 & 38 \\
\hline & ASTK4 & 2135 & 897 & 58 & 61 \\
\hline & & Peak & Peak & Peak & R.M.S. \\
\hline & & $\begin{array}{l}\text { Disp. } \\
(\mathrm{mm})\end{array}$ & $\begin{array}{l}\text { Disp. } \\
(\mathrm{mm})\end{array}$ & $\begin{array}{c}\text { Reduction } \\
(\%)\end{array}$ & $\begin{array}{c}\text { Reduction } \\
(\%)\end{array}$ \\
\hline & Stocker & 101 & 73 & 28 & 66 \\
\hline \multirow{7}{*}{614} & ASTK1 & 2745 & 1097 & 60 & 50 \\
\hline & ASTK2 & 3587 & 1105 & 69 & 69 \\
\hline & ASTK3 & 2365 & 1095 & 54 & 48 \\
\hline & ASTK4 & 3163 & 1076 & 66 & 67 \\
\hline & & Peak & Peak & Peak & R.M.S. \\
\hline & & $\begin{array}{l}\text { Disp. } \\
(\mathrm{mm})\end{array}$ & $\begin{array}{l}\text { Disp. } \\
(\mathrm{mm})\end{array}$ & $\begin{array}{c}\text { Reduction } \\
\quad(\%)\end{array}$ & $\begin{array}{c}\text { Reduction } \\
(\%)\end{array}$ \\
\hline & Stocker & 150 & 99 & 34 & 69 \\
\hline \multirow{7}{*}{717} & ASTK1 & 3205 & 1377 & 57 & 47 \\
\hline & ASTK2 & 4188 & 1321 & 68 & 67 \\
\hline & ASTK3 & 2761 & 1340 & 51 & 44 \\
\hline & ASTK4 & 3693 & 1226 & 67 & 64 \\
\hline & & Peak & Peak & Peak & R.M.S. \\
\hline & & $\begin{array}{l}\text { Disp. } \\
(\mathrm{mm})\end{array}$ & $\begin{array}{l}\text { Disp. } \\
(\mathrm{mm})\end{array}$ & $\begin{array}{c}\text { Reduction } \\
(\%)\end{array}$ & $\begin{array}{c}\text { Reduction } \\
(\%)\end{array}$ \\
\hline & Stocker & 175 & 125 & 29 & 66 \\
\hline
\end{tabular}


Table 3: Frequencies and damping ratios from system identification of the stocker and frame.

\begin{tabular}{|c|c|c|c|c|c|}
\hline $\begin{array}{l}\text { Achieved } \\
\text { PFA (ga1) }\end{array}$ & & Direction & Mode & $\begin{array}{c}\text { Frequency } \\
\qquad(\mathrm{Hz})\end{array}$ & $\begin{array}{c}\text { Damping Ratio } \\
(\%)\end{array}$ \\
\hline \multirow{5}{*}{129} & \multirow{4}{*}{ Stocker } & Translation & 1 & 1.84 & 4.17 \\
\hline & & & 2 & 3.00 & 5.35 \\
\hline & & Rotation & 1 & 1.84 & 5.72 \\
\hline & & & 2 & 3.03 & 2.52 \\
\hline & Frame & Translation & 1 & 3.07 & 0.07 \\
\hline \multirow{5}{*}{217} & \multirow{4}{*}{ Stocker } & Translation & 1 & 1.83 & 5.00 \\
\hline & & & 2 & 3.06 & 3.33 \\
\hline & & Rotation & 1 & 1.83 & 4.81 \\
\hline & & & 2 & 3.03 & 1.53 \\
\hline & Frame & Translation & 1 & 3.07 & 0.24 \\
\hline
\end{tabular}


Table 4: $\underline{\text { Comparison of the stocker's response to Kobe earthquake with PFA }}=88$ gal.

\begin{tabular}{|c|c|c|c|c|}
\hline Achieved & & Test & ETABS & \\
\hline $\begin{array}{l}\text { PFA } \\
\text { (ga1) }\end{array}$ & Sensor & $\begin{array}{c}\text { Peak Acc. } \\
\quad \text { (gal) }\end{array}$ & $\begin{array}{c}\text { Peak Acc. } \\
\quad(\text { gal })\end{array}$ & $\begin{array}{c}\text { Error } \\
(\%)\end{array}$ \\
\hline \multirow{6}{*}{88} & ASTK1 & 393.6 & 415.6 & 5.6 \\
\hline & ASTK2 & 514.2 & 536.3 & 4.3 \\
\hline & ASTK3 & 339.1 & 382.0 & 12.7 \\
\hline & ASTK4 & 453.3 & 491.4 & 8.4 \\
\hline & & $\begin{array}{c}\text { Peak Disp. } \\
\quad(\mathrm{mm})\end{array}$ & $\begin{array}{c}\text { Peak Disp. } \\
\quad(\mathrm{mm})\end{array}$ & $\begin{array}{c}\text { Error } \\
(\%)\end{array}$ \\
\hline & Stocker & 21.5 & 24.2 & 12.5 \\
\hline
\end{tabular}




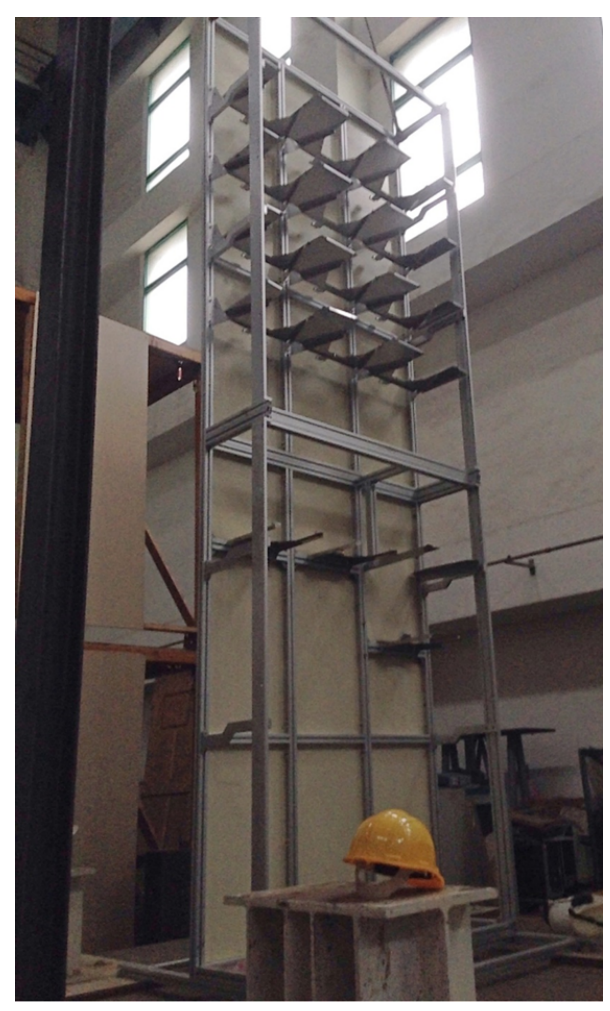

(a) Test stocker

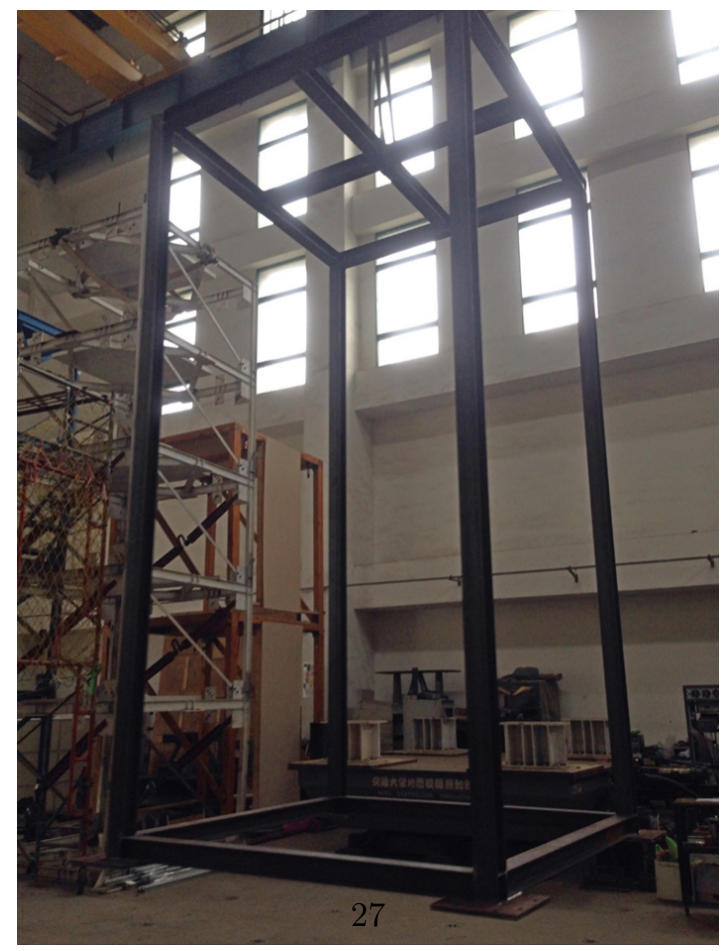

(b) One-story steel frame

Figure 1: Test stocker and one-story steel frame. 


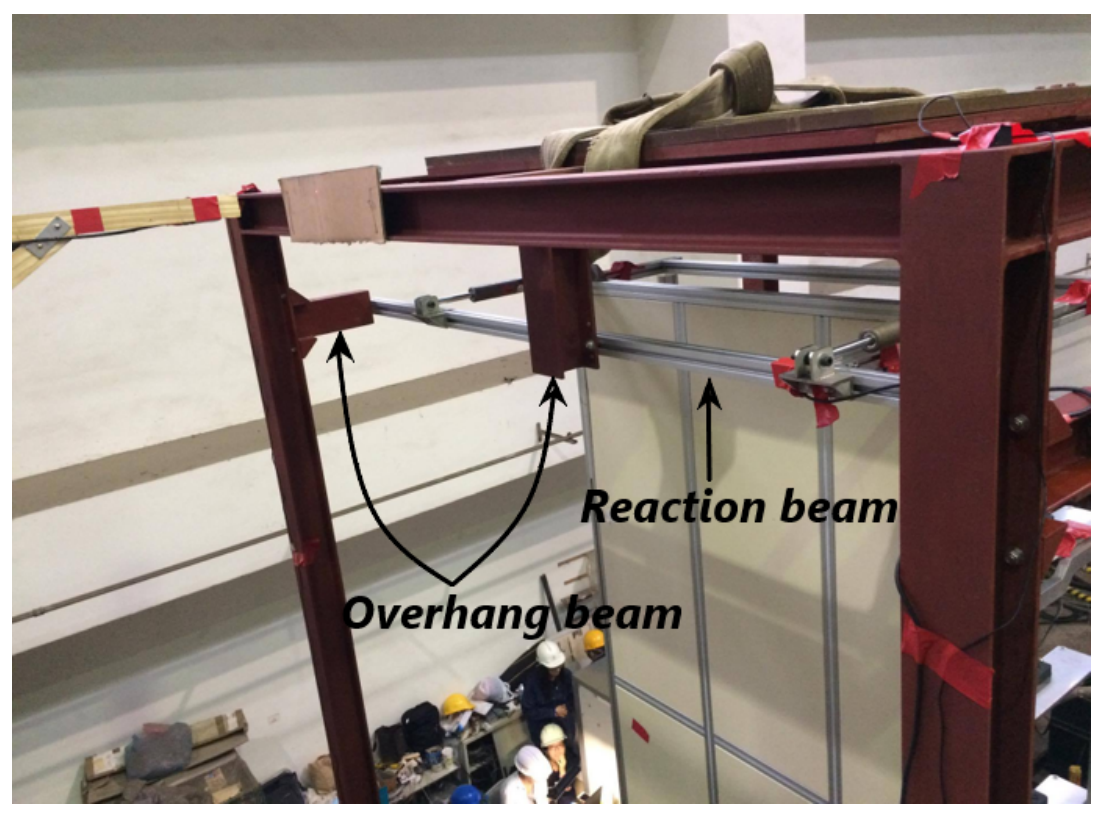

(a) Reaction beam with viscous dampers installed at two ends of the beam

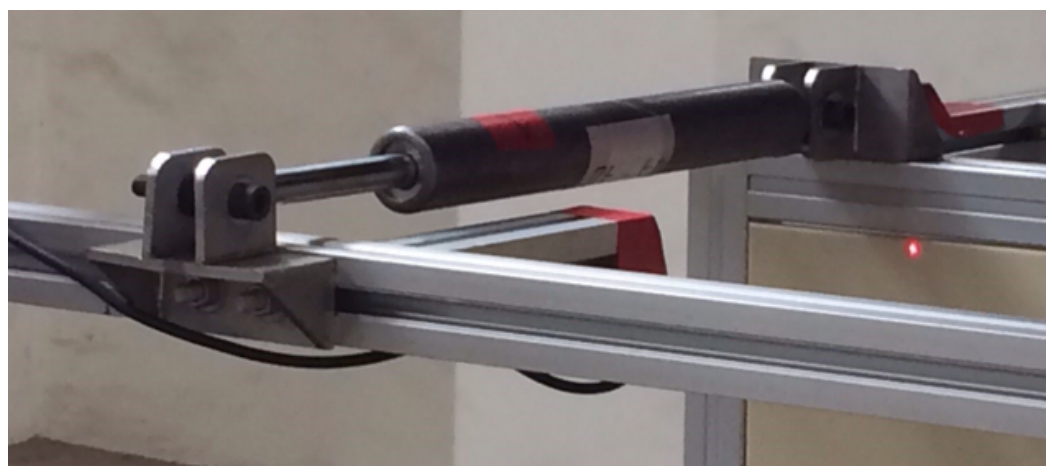

(b) Viscous damper installed in between the reaction beam and top of the stocker

Figure 2: Setup of the reaction beam and viscous dampers 


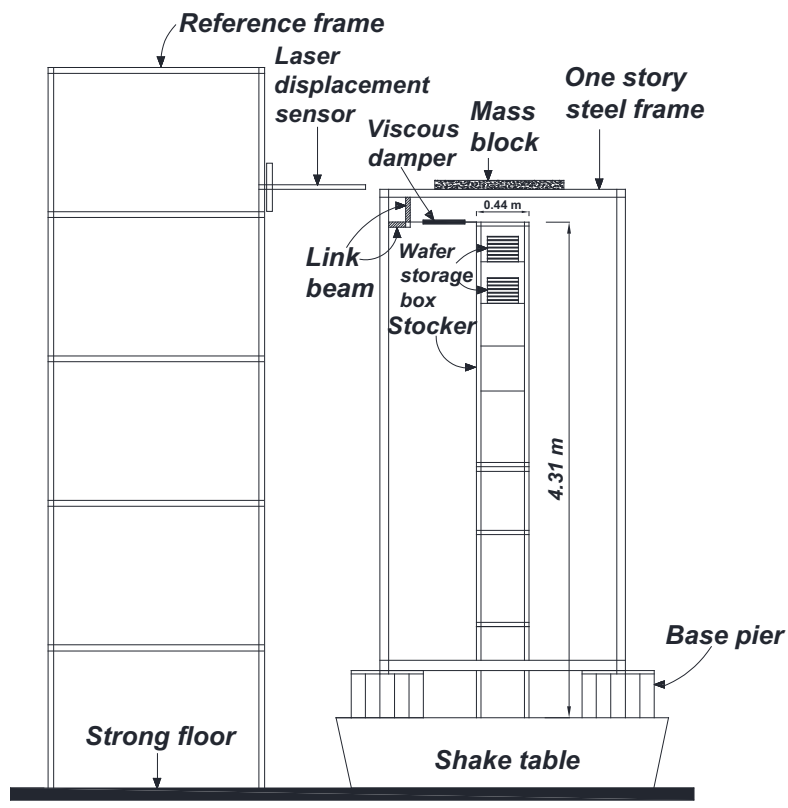

Elevation View

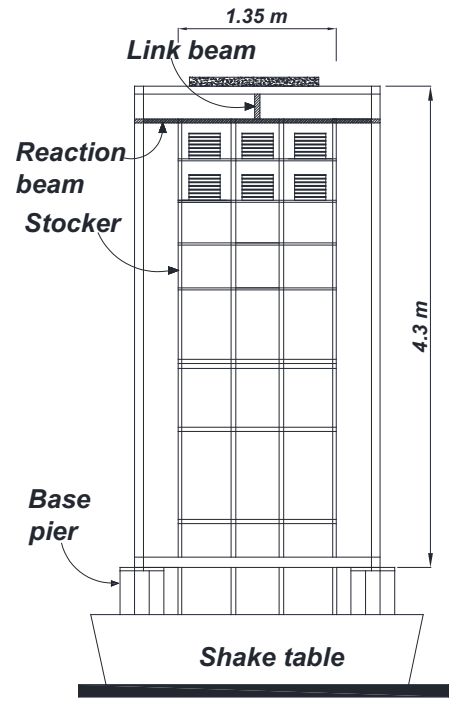

Side View

Figure 3: Configuration of the test specimen. 


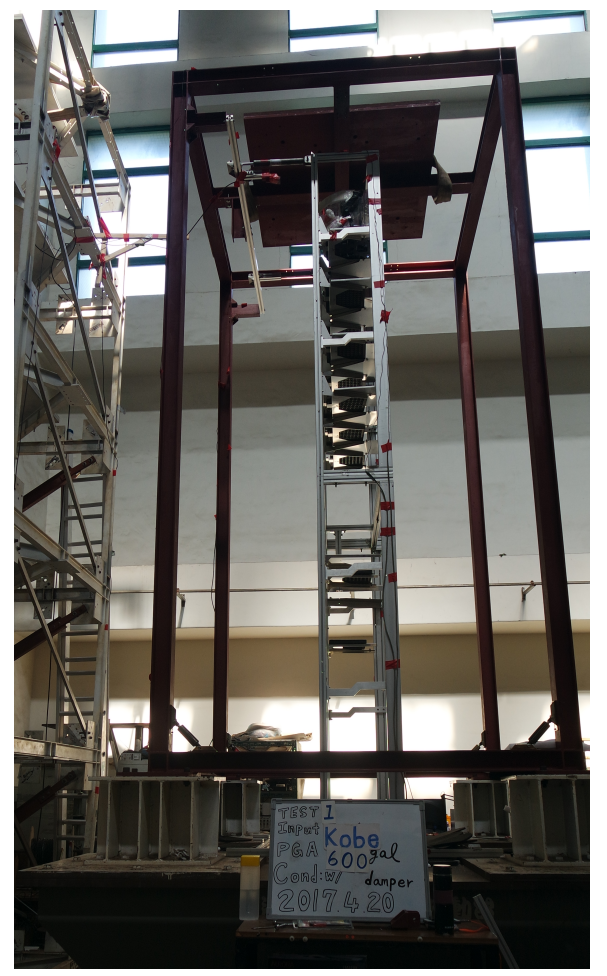

(a) Elevation view

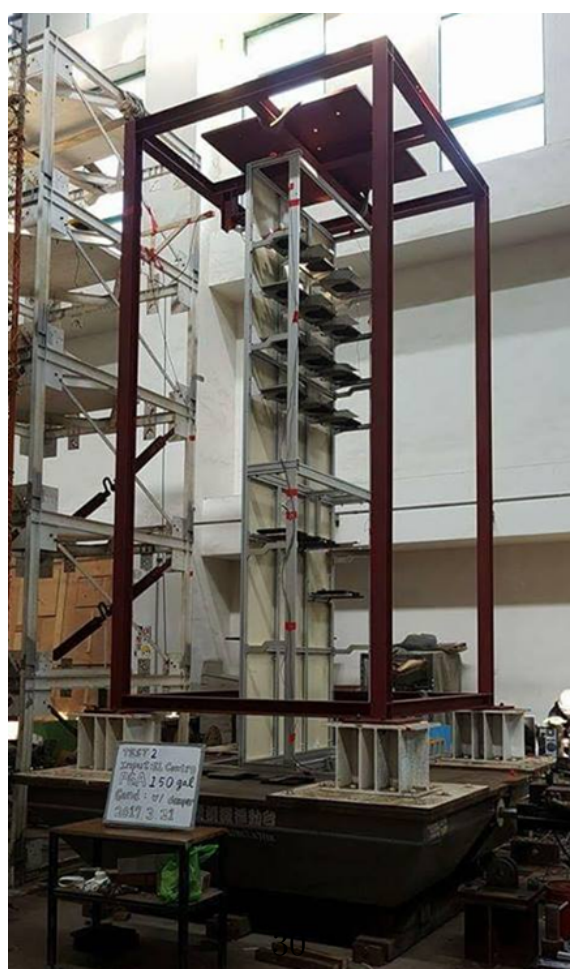

(b) Final test setup

Figure 4: Photographs of the final test setup. 


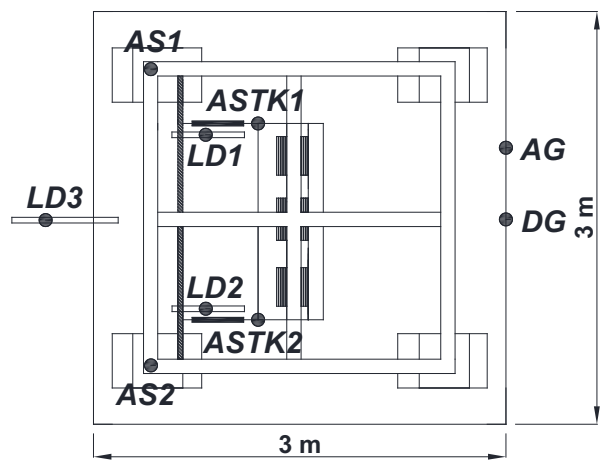

Top View

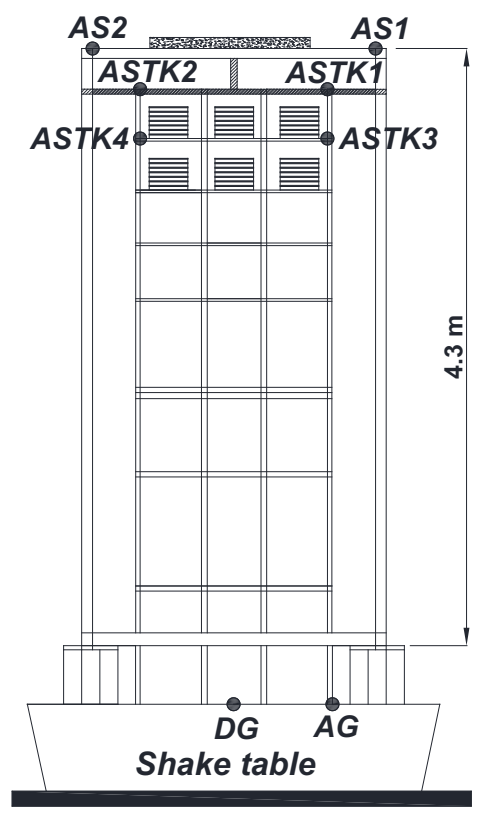

Side View

Figure 5: Sensor instrumentation of the frame and stocker. 


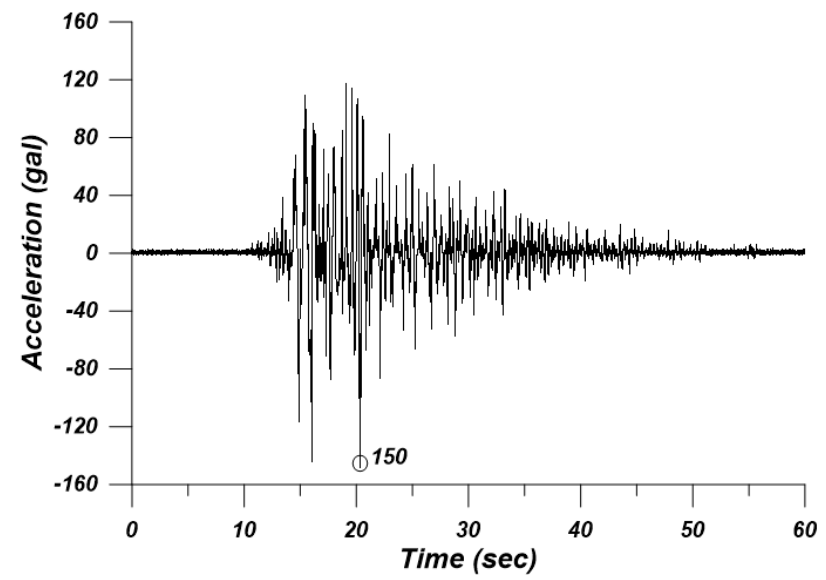

(a) Acceleration time history scaled to 150 gal

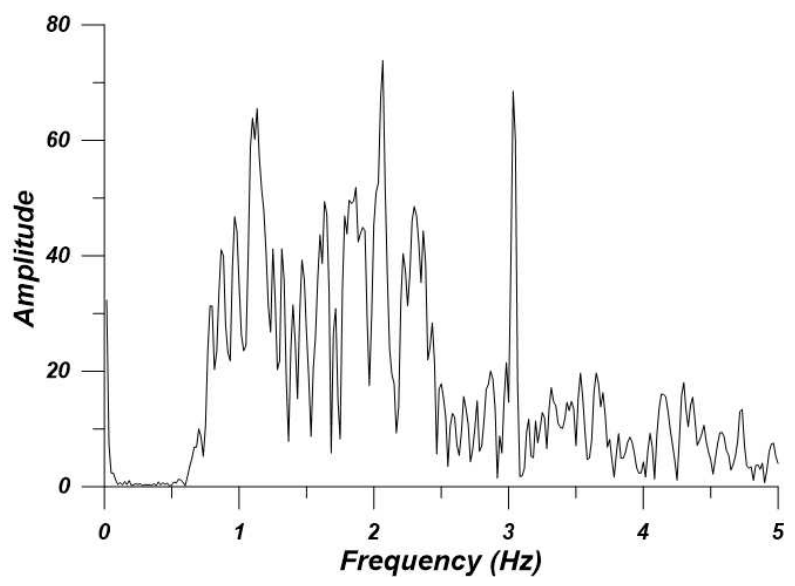

(b) Fourier amplitude spectrum

Figure 6: Acceleration time history and amplitude spectrum of the 1995 Kobe earthquake. 


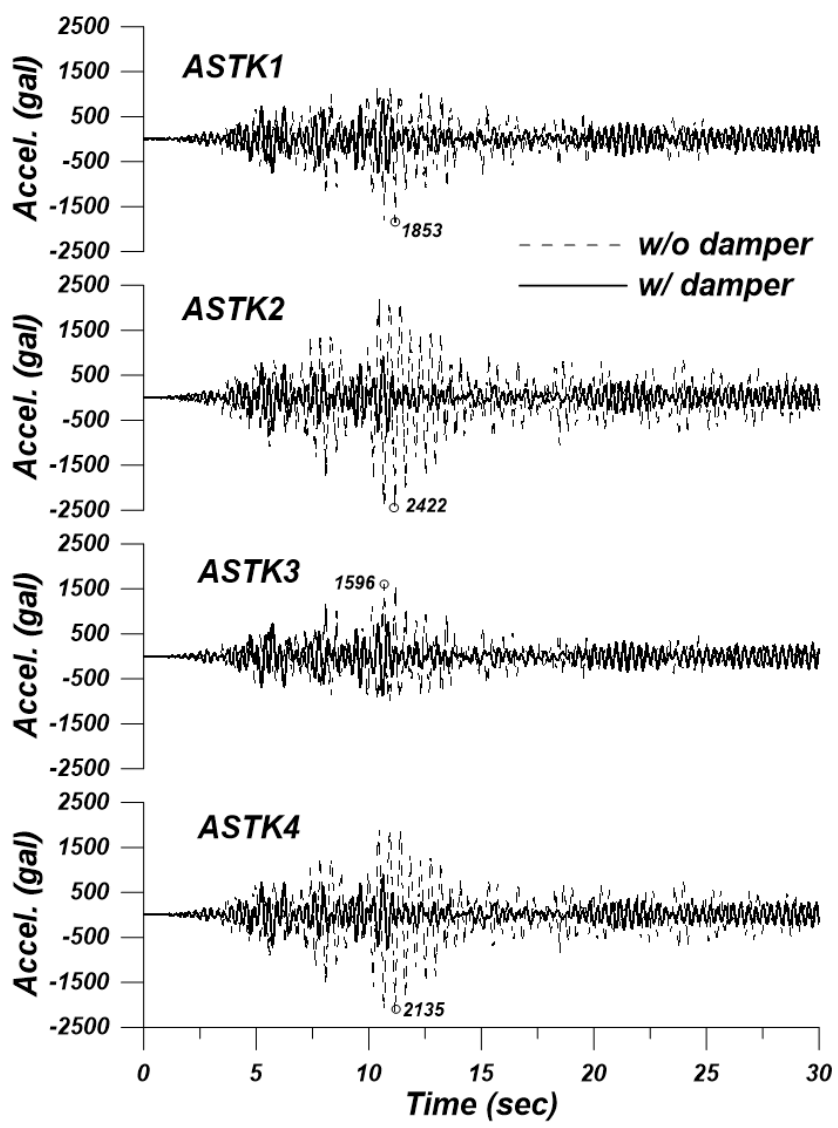

(a) Acceleration responses for stocker top and top shelf

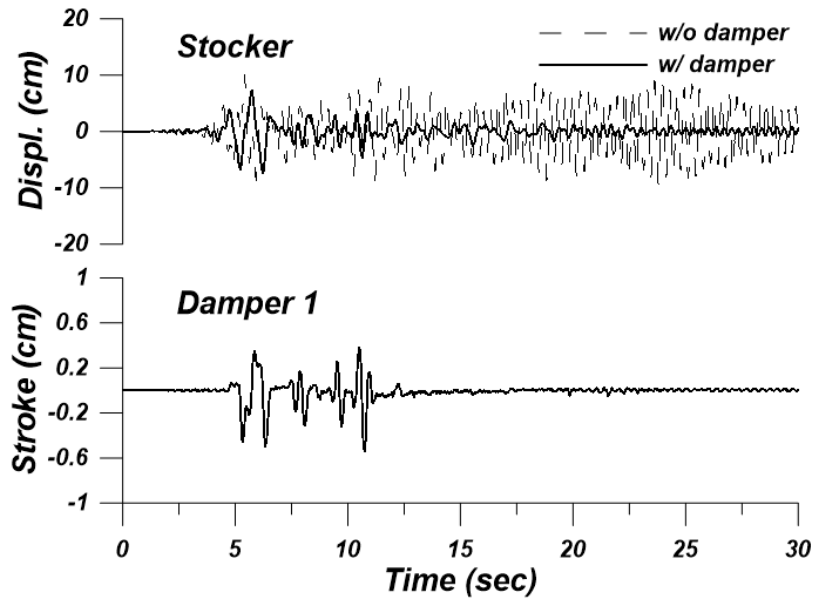

(b) Displacement response of the stocker and damper stroke

Figure 7: Comparison of response acceleration and displacement of the stocker subjected to Kobe earthquake with PFA=416 gal. 


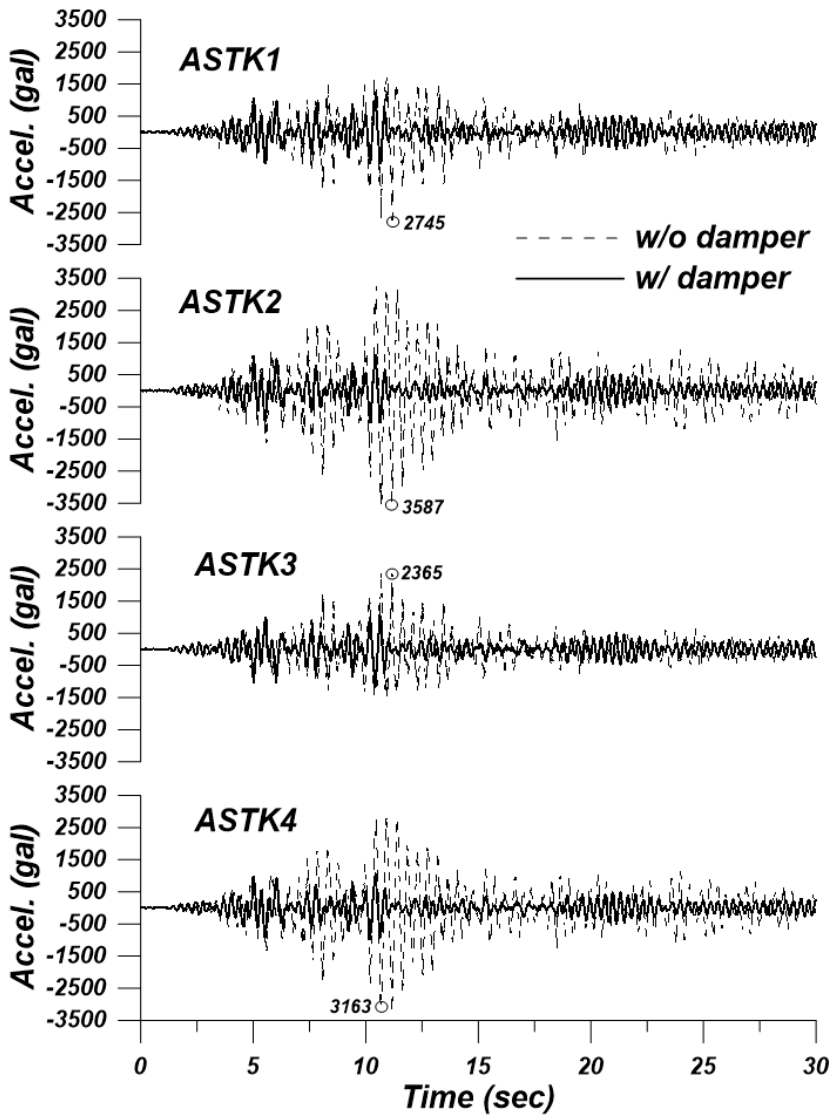

(a) Acceleration responses for stocker top and top shelf

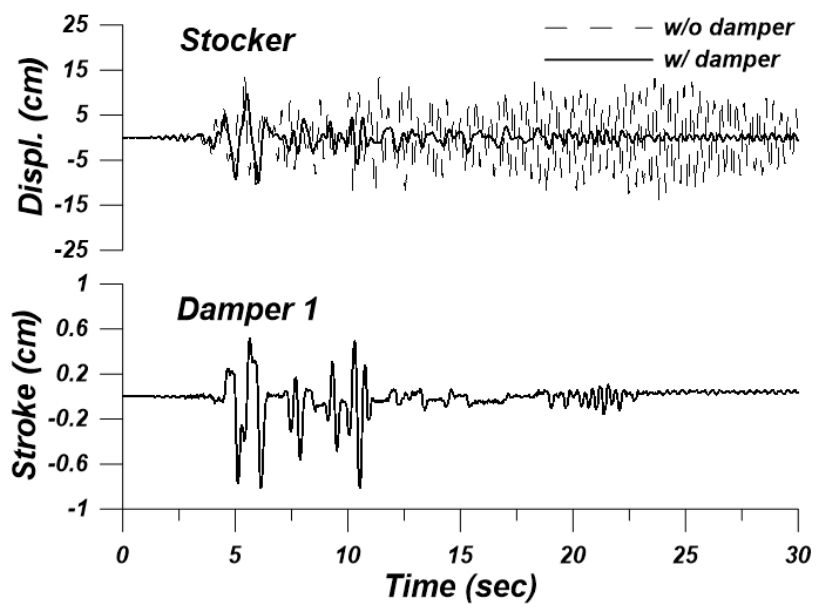

(b) Displacement response of the stocker and damper stroke

Figure 8: Comparison of response acceleration and displacement of the stocker subjected to Kobe earthquake with PFA=614 gal. 


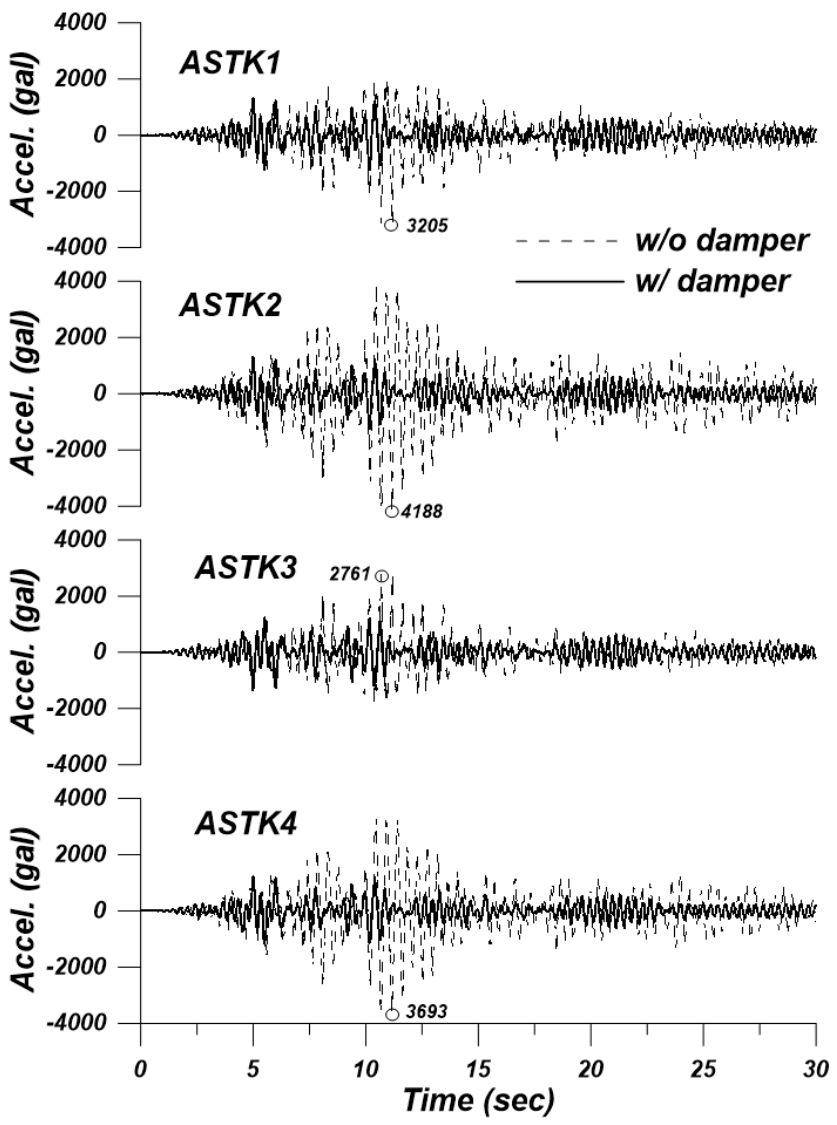

(a) Acceleration responses for stocker top and top shelf

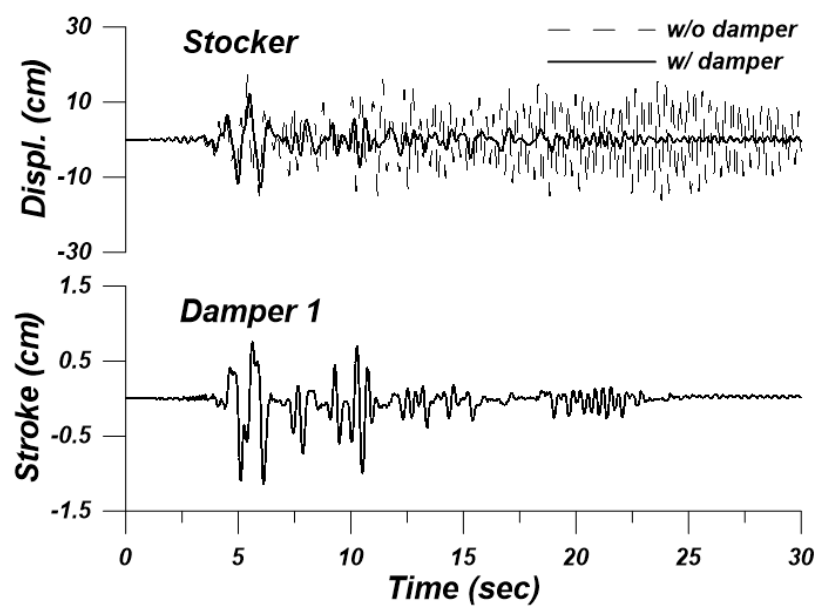

(b) Displacement response of the stocker and damper stroke

Figure 9: Comparison of response acceleration and displacement of the stocker subjected to Kobe earthquake with $\mathrm{PFA}=717$ gal. 

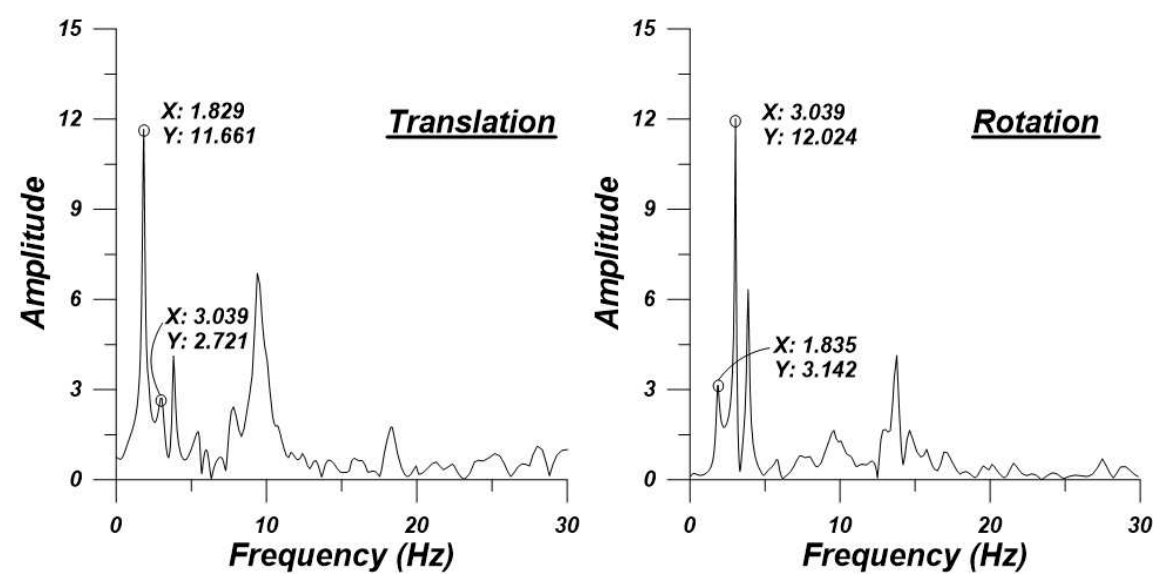

(a) Translation $(\mathrm{PFA}=129$ gal $)$

(b) Rotation $(\mathrm{PFA}=129$ gal $)$
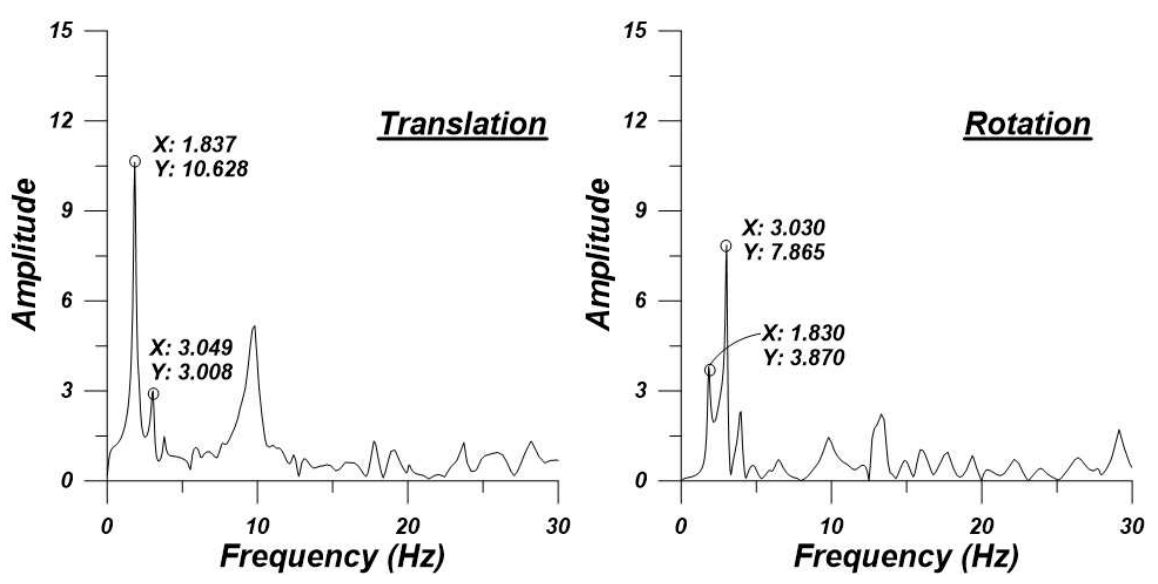

(c) Translation $(\mathrm{PFA}=217$ gal $)$

(d) Rotation $(\mathrm{PFA}=217$ gal $)$

Figure 10: System Identification of the stocker subjected to Kobe Earthquake. 


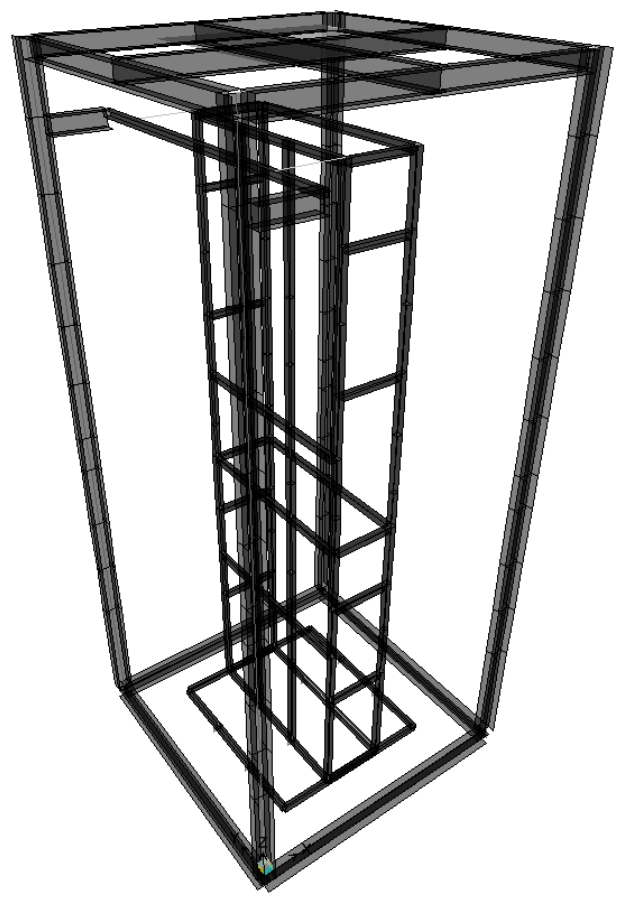

(a) Frame and stocker model

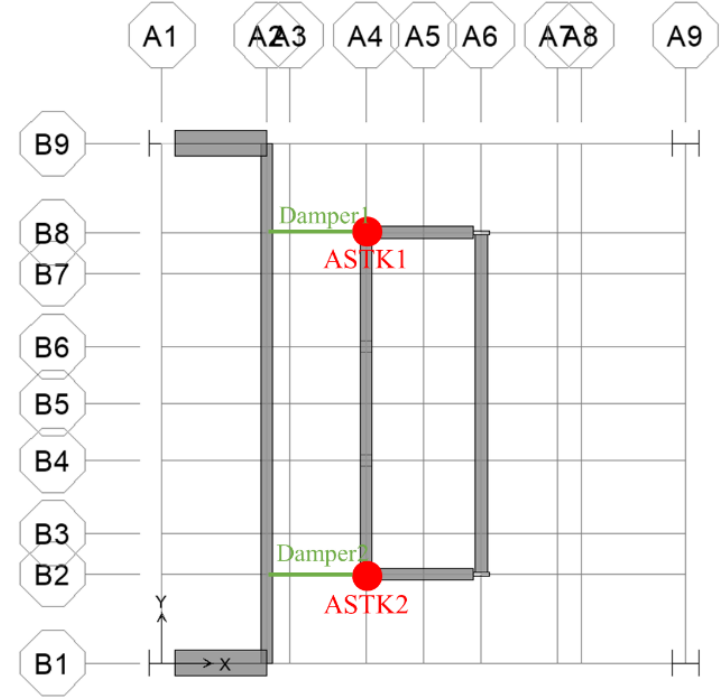

(b) Top view of sensor location

Figure 11: The built frame and stocker model in ETABS 


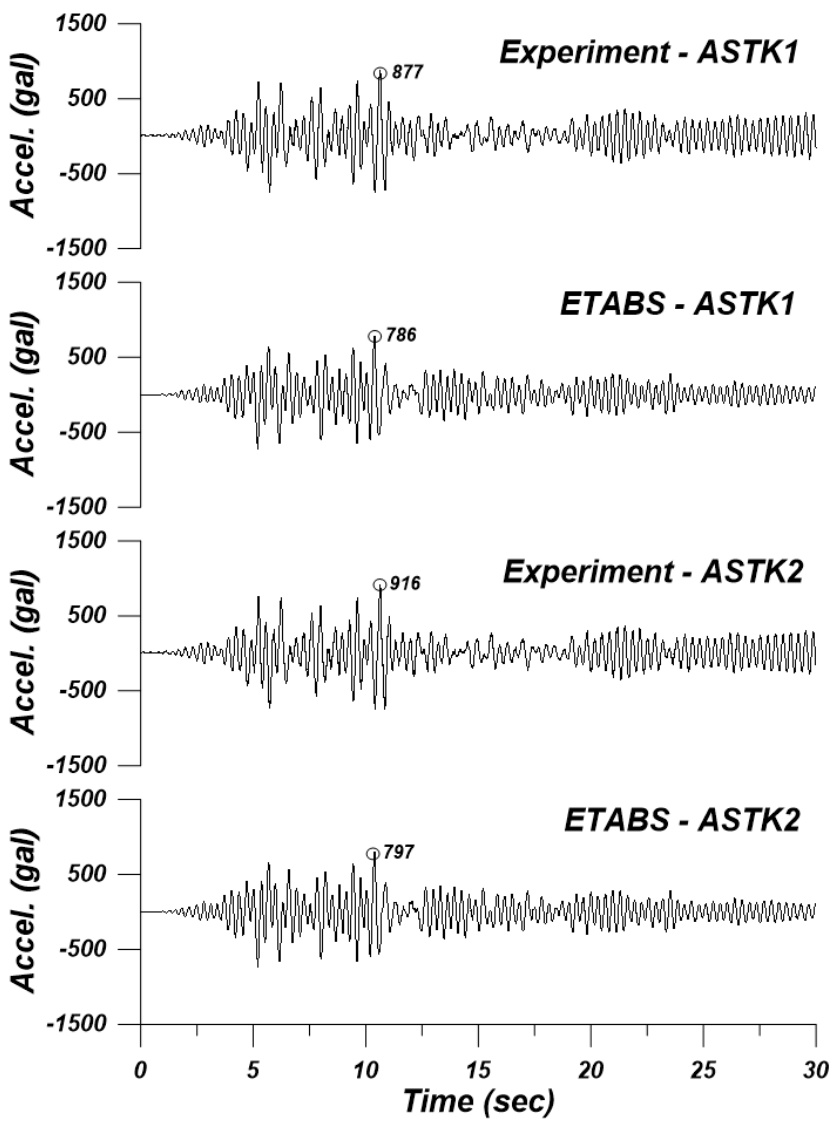

(a) Acceleration response of the stocker top

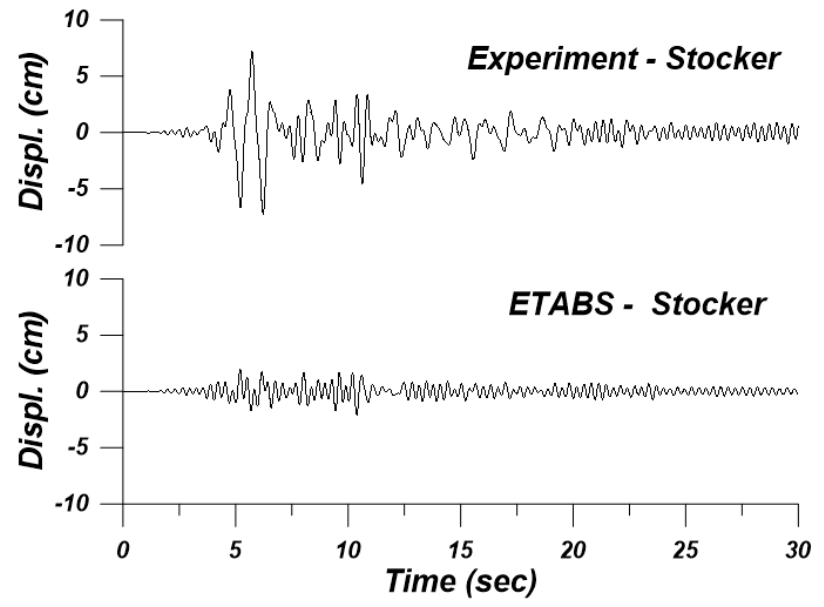

(b) Displacement response of the stocker

Figure 12: Comparison of response acceleration and displacement of the stocker subjected to Kobe earthquake with $\mathrm{PFA}=416$ gal. 38 


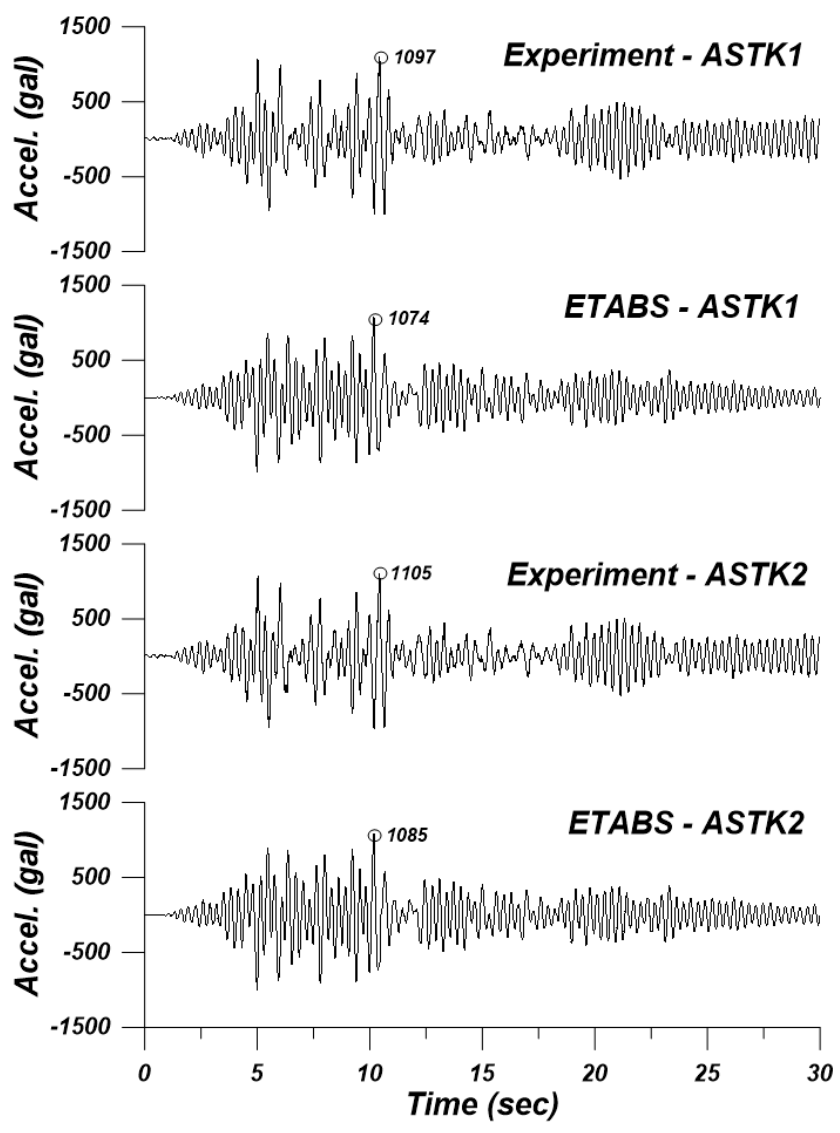

(a) Acceleration response of the stocker top

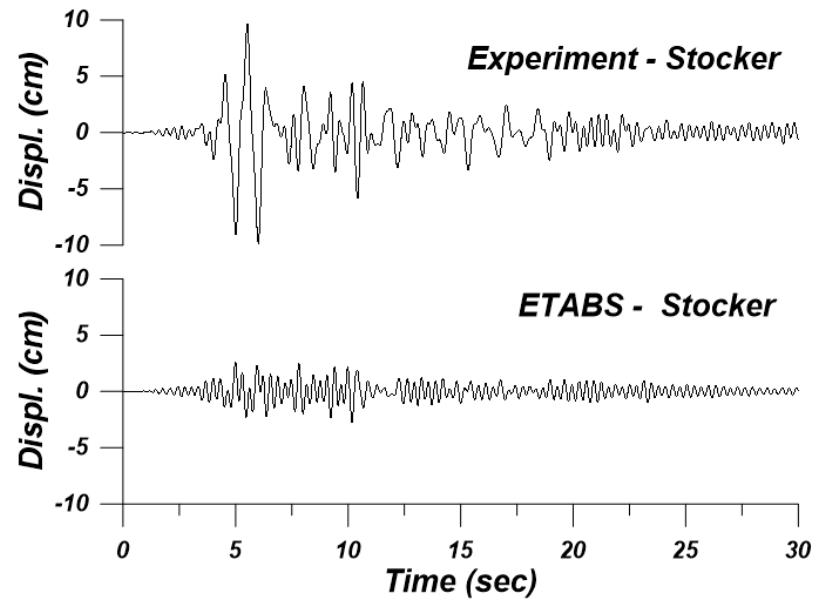

(b) Displacement response of the stocker

Figure 13: Comparison of response acceleration and displacement of the stocker subjected to Kobe earthquake with PFA=614 gal. 

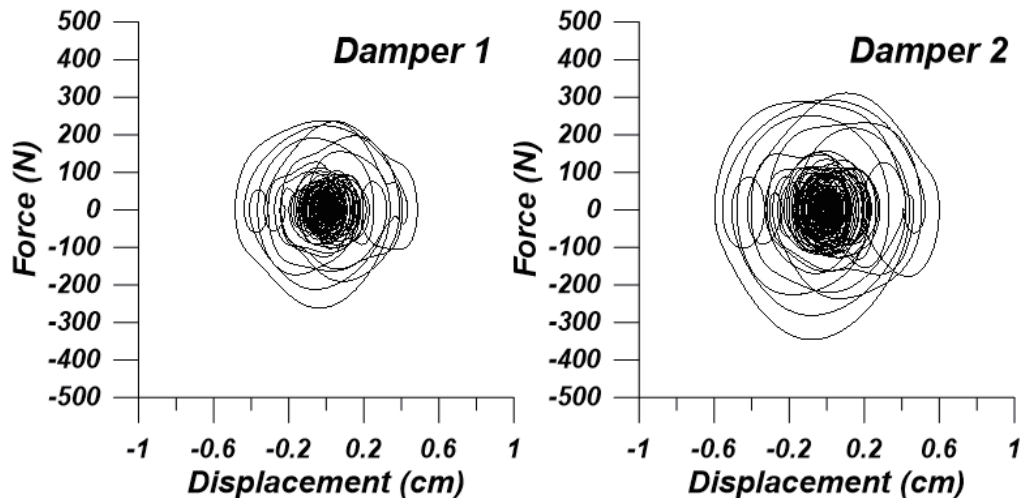

(a) $\mathrm{PFA}=416$ gal
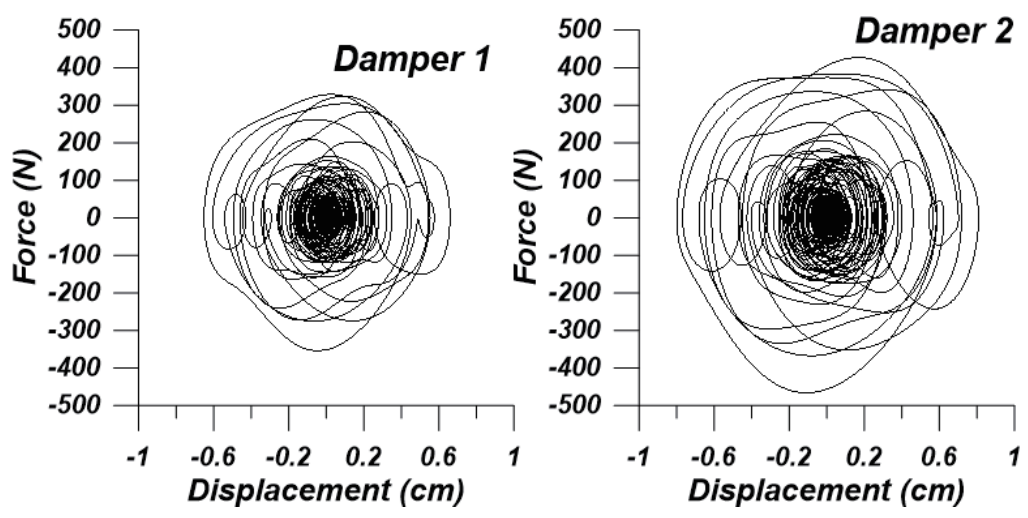

(b) $\mathrm{PFA}=614$ gal

Figure 14: Hysteresis loops of the dampers subjected to Kobe earthquake 